\title{
Role of axoplasmic transport in the pathophysiology of ischaemic disc swelling
}

\author{
DAVID MCLEOD, JOHN MARSHALL, AND EVA M. KOHNER \\ From Moorfields Eye Hospital, the Department of Visual Science, Institute of Ophthalmology, \\ and the Department of Medicine, Royal Postgraduate Medical School, London
}

SUMMARY Pathological changes in the optic disc and anterior part of the optic nerve of monkeys were studied 5 hours and several days after occlusion of the temporal short posterior ciliary arteries. Ischaemic vacuolation of neural tissue was observed in some of the animals studied and was restricted to the lamina cribrosa and the immediately retrolaminar portion of the optic nerve. Axonal swelling and organelle aggregation were demonstrated in the prelaminar region, and autoradiography after intravitreal injection of tritiated leucine revealed an associated obstruction of rapid and slow orthograde axoplasmic transport. The experimental findings correlate with those seen clinically in acute ischaemic optic neuropathy. The pale swelling of the optic disc in this condition represents an accumulation of axoplasmic debris in retinal ganglion-cell axons owing to obstruction of axoplasmic transport at the lamina cribrosa; it is thus equivalent to a 'cotton-wool spot' of the disc.

Acute ischaemic optic neuropathy (ION), characterised by sudden visual loss and pale disc swelling, results from obstruction of the blood supply to the anterior part of the optic nerve..$^{1-3}$ This is confirmed by necropsy studies in patients with ION, which show occlusion of the lumen of the posterior ciliary arteries (PCAs) and also necrosis of the most anterior part of the retrolaminar myelinated optic nerve. ${ }^{4-10}$ However, these studies have failed to clarify the nature of the ophthalmoscopically visible prelaminar swelling in ION. This sign was previously interpreted as an infarct of the disc, ${ }^{311}$ but more recently the prelaminar swelling has been attributed to an accumulation of opaque axoplasmic debris in the optic nerve head rather than infarction..$^{12}{ }^{13} \mathrm{In}$ an attempt to resolve this issue, and since the immediate sequelae of experimental PCA occlusion have received scant attention in the past, we have reinvestigated acute ischaemic disc swelling in primates.

\section{Material and methods}

Cynomolgus and rhesus monkeys were used in these experiments, since their ocular vascular anatomy corresponds reasonably well with that of man.

Lateral orbitotomies were performed in order to

Correspondence to $\mathrm{Mr}$ D. McLeod, FRCS, Moorfields Eye Hospital, City Road, London ECIV 2PD. expose the temporal aspect of the optic nerve in 11 animals; the lateral rectus and inferior oblique muscles were routinely severed. All the short PCAs visible on the temporal, superior, and inferior aspects of the optic nerve were divided after coagulation by bipolar diathermy together with small vessels on the sclera around the insertion of the optic nerve. Care was taken to avoid damage to the dural sheath of the optic nerve and the underlying pial vasculature. In all experiments the short PCAs on the medial aspect of the optic nerve were spared so that 'control' data could be obtained. This was important, since the eye usually became hypotonic after orbitotomy and vascular occlusion. Occlusion of only the most accessible short PCAs also minimised mechanically induced changes in the optic nerve. Control data were also obtained by carrying out lateral orbitotomy and orbital dissection (but no vascular occlusion) in 5 eyes.

Fluorescein fundus angiography was performed within 1 hour of ciliary occlusion in all animals; $10 \%$ fluorescein solution was injected into a leg vein. The photographic methods have been described in a previous publication. ${ }^{14}$

$0.25 \mathrm{ml}$ of $\mathrm{L}-4,5{ }^{3} \mathrm{H}$-leucine (specific activity 40-60000 m Ci/mmol, Radio Chemical Centre, Amersham) was injected into the posterior vitreous after ocular massage via a 27 gauge needle inserted through the temporal pars plana. The injection was made over the optic disc and was continuously 
Table 1 Details of 11 eyes undergoing temporal short PCA occlusion

\begin{tabular}{|c|c|c|c|c|c|c|}
\hline Number & Type & Eye & $\begin{array}{l}\text { Duration of } \\
\text { occlusion }\end{array}$ & $\begin{array}{l}\text { Preocclusion } \\
{ }^{8} \text { H-leucine }\end{array}$ & $\begin{array}{l}\text { Retrolaminar } \\
\text { infarct }\end{array}$ & Figure \\
\hline 1 & Cynomolgus & Right & 5 hours & $\frac{1}{2} h$ & + & $4,5,7 b$ \\
\hline 2 & Cynomolgus & Left & 5 hours & $48 \mathrm{~h}$ & - & 3 \\
\hline 3 & Rhesus & Left & 5 hours & $\frac{1}{2} h$ & - & \\
\hline 4 & Rhesus & Left & 5 hours & $\frac{1}{2} h$ & - & \\
\hline 5 & Rhesus & Right & 5 hours & $\frac{1}{2} h$ & + & $6,7 a$ \\
\hline 6 & Cynomolgus & Left & 4 days & $48 \mathrm{~h}$ & \pm & 2 \\
\hline 7 & Cynomolgus & Right & 4 days & $48 \mathrm{~h}$ & - & \\
\hline 8 & Rhesus & Left & 4 days & $\frac{1}{2} h$ & + & $1,9 a$ \\
\hline 9 & Cynomolgus & Right & 4 days & $\frac{1}{2} h$ & - & \\
\hline 10 & Rhesus & Right & 4 days & $\frac{1}{2} h$ & - & \\
\hline 11 & Cynomolgus & Left & 7 days & $\frac{1}{2}$ & + & $9 b$ \\
\hline
\end{tabular}

monitored by indirect ophthalmoscopy, care being taken to ensure that central arterial perfusion was maintained at the termination of the injection. The ${ }^{3} \mathrm{H}$-leucine was injected immediately before the ciliary occlusion in 8 eyes, or $\mathbf{4 8}$ hours before the vascular occlusion in 3 eyes (Table 1).

In acute experiments ( 5 eyes) the ischaemic lesion was allowed to develop for 5 hours before enucleation of the eye. In chronic experiments the ischaemic lesion developed for either 4 days (in 5 eyes) or 7 days (in 1 eye) before enucleation. Colour photographs of the fundus and further fluorescein angiograms were obtained during the interim period.

The eyes, including as long a length as possible of the optic nerve, were removed at the termination of the experiments, and after transcorneal incision were immediately immersed in $100 \mathrm{ml}$ of $2.5 \%$ gluteraldehyde buffered in $0.1 \mathrm{M}$ sodium cacodylate with a final $\mathrm{pH} 7 \cdot 4$. The eyes were progressively dissected in this solution, and after 1 hour the discs and optic nerves were isolated and then hemisected in the horizontal aspect. Thus during subsequent microscopy both temporal and nasal retina could be viewed simultaneously. In some eyes, where either an inferior or superior sectorial defect was suspected, the relevant half of the disc was quartered by an incision along the axis of the retinal nerve fibres. Subsequent histological and autoradiographic processing has been previously described. $^{15}$

\section{Results}

FUNDUS CHANGES AFTER PCA OCCLUSION Apart from slight hyperaemia there were no dis- cernible changes in the ophthalmoscopic appearance of the optic disc and retina during the first few hours following occlusion of the temporal short PCAs. In the chronic experiments swelling of the optic nerve head was observed in 2 animals, the inferotemporal part of the disc being particularly involved (Fig. 1). Outer retinal infarcts were observed in all eyes in chronic experiments, though there was great variation in the extent of these changes; in none was there involvement of the immediately peripapillary retina.

\section{FLUORESCEIN ANGIOGRAPHY AFTER PCA OCCLUSION}

In all eyes nonfilling of the temporal choroid in the early part of the central arterial transit confirmed the vascular obstruction (Fig. 2a). The choriocapillaris filling from the nasal short PCAs was contiguous with the adjacent margin of the optic disc and was initially sharply demarcated. Subsequently, however, the extent of choriocapillaris filling with fluorescein increased (Fig. 2b) and eventually included an area at least 1 disc diameter in width around the temporal aspect of the optic disc. Thus in all animals the immediately peripapillary choriocapillaris was completely filled by the late venous phase of the dye transit, and in some animals much more extensive filling of the temporal choroid was demonstrated.

Changes in fluorescein filling of the optic disc after PCA occlusion were generally more difficult to define because the central arterial supply to the superficial disc tissue obscured the filling pattern deeper in the optic nerve head after 2 or 3 frames. In 3 eyes, however, there was unequivocal filling 

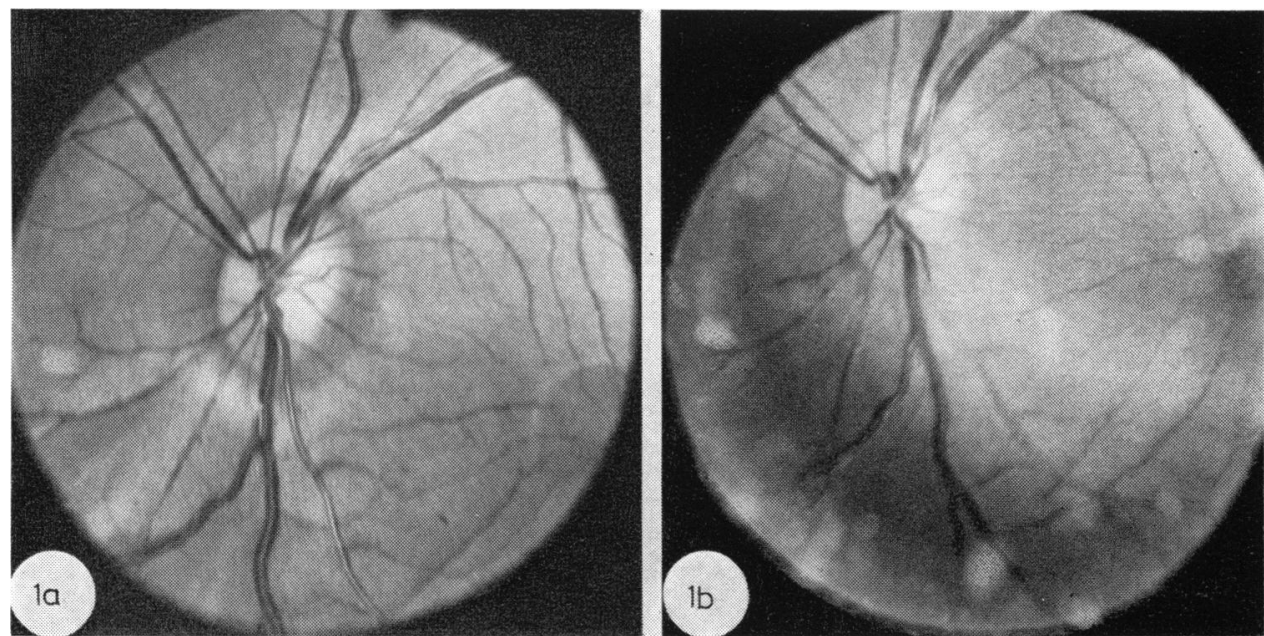

Fig. 1 Photographs of left optic disc of rhesus monkey: (a) Preoperative appearance.

(b) Appearance 4 days after temporal short PCA occlusion; swelling of temporal half of disc, particularly inferotemporal quadrant

of the nasal part of the disc contiguous with the filled choriocapillaris at a stage early in the dye transit in which the temporal half of the disc could be seen to be nonperfused (Fig. 2a). This reversed the pattern of fluorescein filling in control fluorescein angiograms taken before vascular occlusion.

\section{ACUTE HISTOPATHOLOGY}

\section{Light microscopy}

The histological findings 5 hours after PCA occlusion showed considerable variation. In 3 eyes there were no visible changes in the prelaminar, laminar, or retrolaminar portions of the nerve (Fig. 3), while in 2 others changes were apparent (Table 1). In neither group, however, was there any gross distortion of the topography of the disc or any apparent involvement of the peripapillary retina.

As retinal ganglion-cell axons pass back through the retinal layers at the disc, some exhibit a slight increase in diameter, so it may be difficult to discriminate between such normal expansions and any that may have been induced by experimental
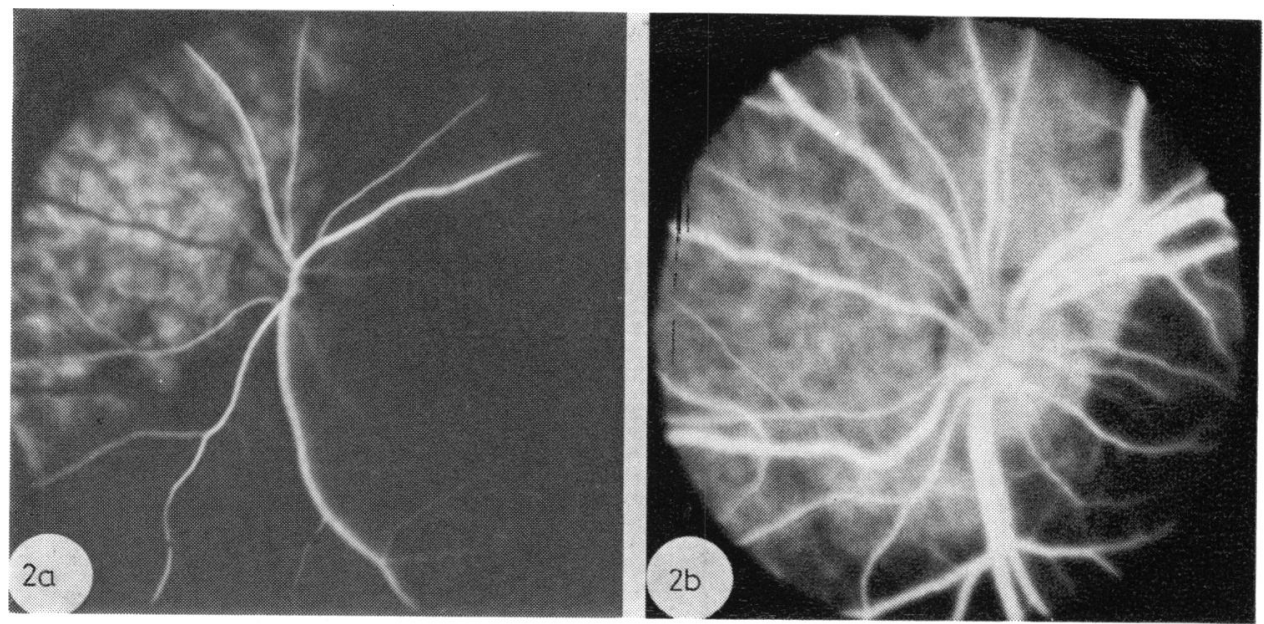

Fig. 2 Fluorescein angiograms 1 hour after temporal short PCA occlusion: (a) Early retinal arterial phase; nasal choriocapillaris and prelaminar circulation filling with dye; no filling of temporal choroid and disc. (b) Retinal venous phase; extension of filling of choriocapillaris into temporal peripapillary region. 

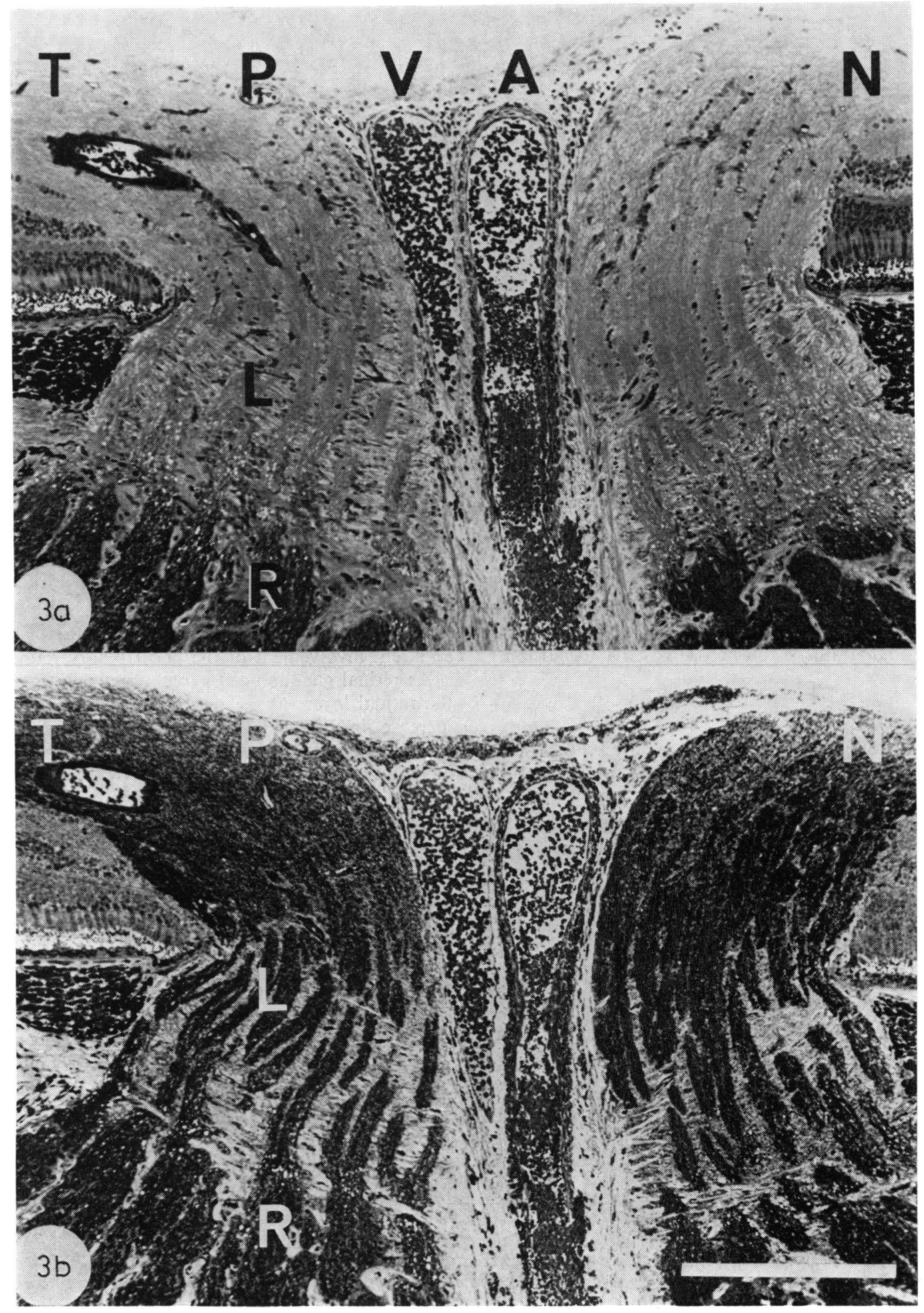
procedures. In the 2 eyes showing damage there was an increase in both the diameter and staining density of many of the axons on the temporal side of the disc. In these animals, however, changes were most marked in the laminar and retrolaminar regions and in both cases were confined to the temporal half of the nerve (Fig. 4). Within the lamina many axons became progressively more vacuolated as they approached the retrolaminar portion of the nerve, but in both eyes some normal-looking axons were found. The glial elements in the lamina appeared relatively unaffected but occasionally showed slight irregularities in staining.

In the retrolaminar portion of the affected nerves, the myelinated axons on the temporal side were grossly vacuolated (Fig. 4a, b). At the periphery of this part of the nerve, however, many normallooking axons were observed adjacent to the pia. In contrast, at the centre of the nerves there was an abrupt transition between normal and damaged axons. The axial extent of the vacuolated part of the nerve varied from $1 \frac{1}{2}$ to $4 \mathrm{~mm}$, and the posterior margin of damage consisted of a region of diffuse and dissociated vacuoles which gradually became less numerous.

\section{Electron microscopy}

In the unmyelinated prelaminar region individual axons normally contain large numbers of small mitochondria. In eyes showing damage an increase in mitochondrial numbers was noted as fibres approached the lamina on the temporal side. These mitochondria were smaller than normal, and many were electron-dense and looked degenerate. In association with these mitochondrial aggregates were many membrane-bound vesicles. Glial cells in the prelaminar region appeared unaffected by the experimental procedure.

As the fibres traversed the lamina, the mitochondria became progressively more degenerate, forming either condensed aggregates adjacent to the boundary membranes of the axons, or swollen

Fig. 3 Light micrographs of nerve showing no damage 5 hours after temporal short PCA occlusion: (a) Anterior portion of nerve sectioned in the horizontal plane and showing both temporal (T) and nasal (N) retina; prelaminar $(\mathrm{P})$, laminar $(L)$, and retrolaminar (R) portions of nerve identified; also central retinal vein (V) and artery (A). (b) Autoradiograph of same specimen (tritiated leucine injected intravitreally 53 hours prior to enucleation); relatively greater density of grain over axons on nasal side of prelaminar portion of the nerve (P). (Designations as in Fig. 3a; bar marker is $300 \mu \mathrm{m})$ and vacuolated masses at the core of the axon surrounded by vesicles. Towards the retrolaminar region the microvacuolations within axonal organelles became confluent and began to disrupt the entire axonal cytoplasm (Fig. 5). Some glial cells within the lamina also showed microvacuolation.

In the vacuolated retrolaminar region the cytoplasmic contents of the axons had been lost. Thus affected fibres appeared as well-preserved but distended myelin sheaths surrounding amorphous granular cytoplasmic debris in which occasional disrupted mitochondria were observed. As seen in the light micrographs, the distal edge of this region was diffuse, and no significant changes were observed in the axons where they returned to a more normal configuration.

\section{Autoradiography}

In unaffected and control nerves those portions of the disc receiving axons from the nasal retina were associated with a higher concentration of grains than those receiving inputs from the temporal fields (Fig. 3b). This observation may appear contrary to expectation given the high concentration of ganglion cells in the macula (Fig. 6). However, it was a consistent finding and possibly reflects differences in the speeds of rapid cellulifugal axonal flow on the nasal compared with the temporal side. It might also result from a greater labelled contribution in axonal material in our experimental time period due to less competition in obtaining radiolabelled protein in the sparse population of ganglion cells on the nasal side. In addition there was a slight increase in grain density over the prelaminar axons immediately adjacent to the lamina in all discs examined. This suggests that the lamina is the site of a natural constraint to the flow of materials in retinal ganglion-cell axons.

In those eyes in which a successful lesion had been produced, an extremely dense and highly localised concentration of silver grains was found on the temporal side of the disc in the prelaminar region immediately adjacent to the lamina (Fig. 7). The grain density on the experimental side was far in excess of that either on the collateral side or in the same region in control tissue. With increasing distance anteriorly from the lamina there was a progressive decrease in grain density, but there was an abrupt loss of grains over the vacuolated regions of the lamina and retrolaminar region (Fig. 7). Some grains were found in the vacuolated regions, but these were always associated with the few normal-looking axons. On the experimental side of the nerve no grains were observed over involved axons distal to the vacuolated region. The autoradiographic findings are summarised in Fig. 8. 

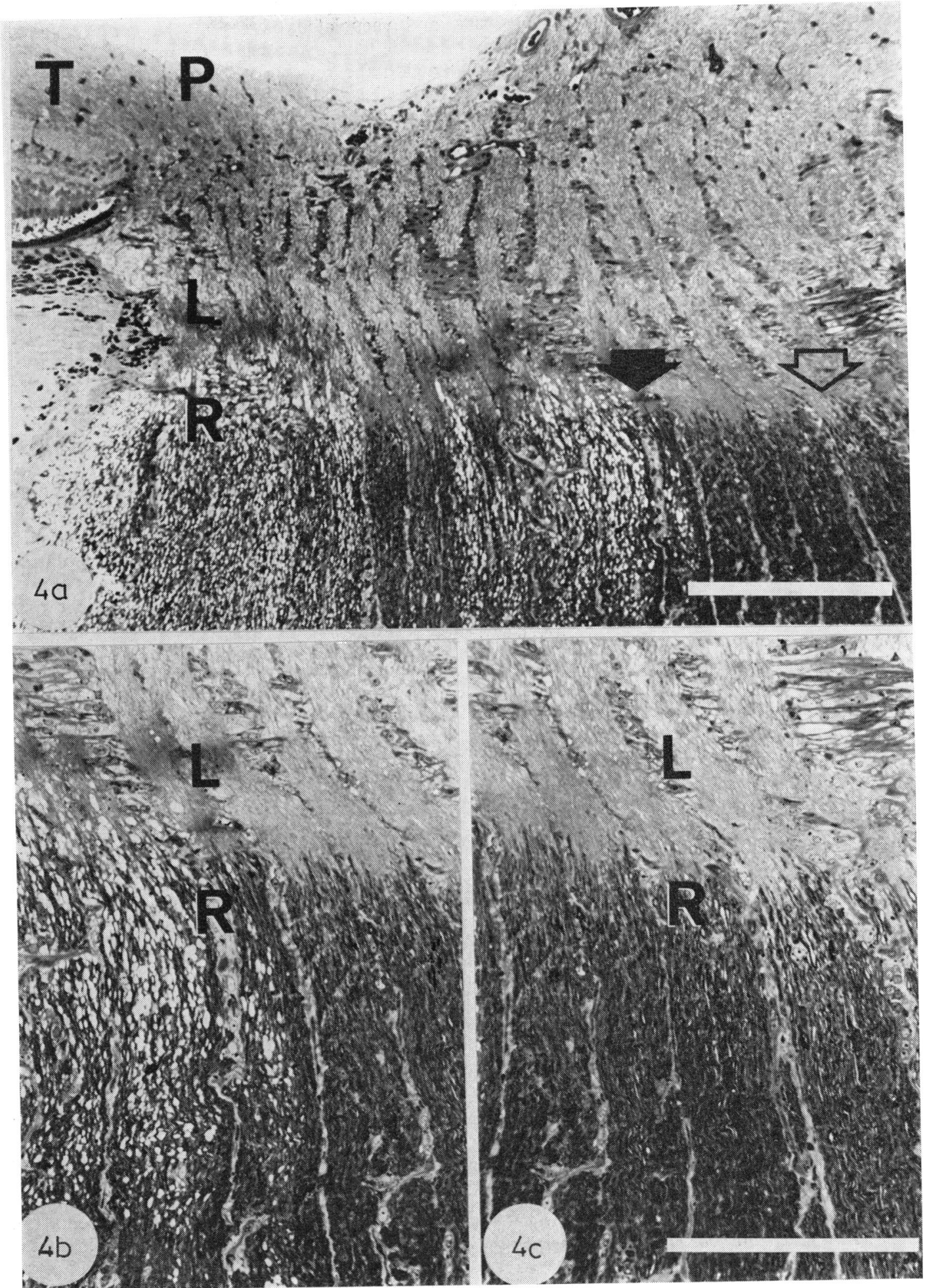


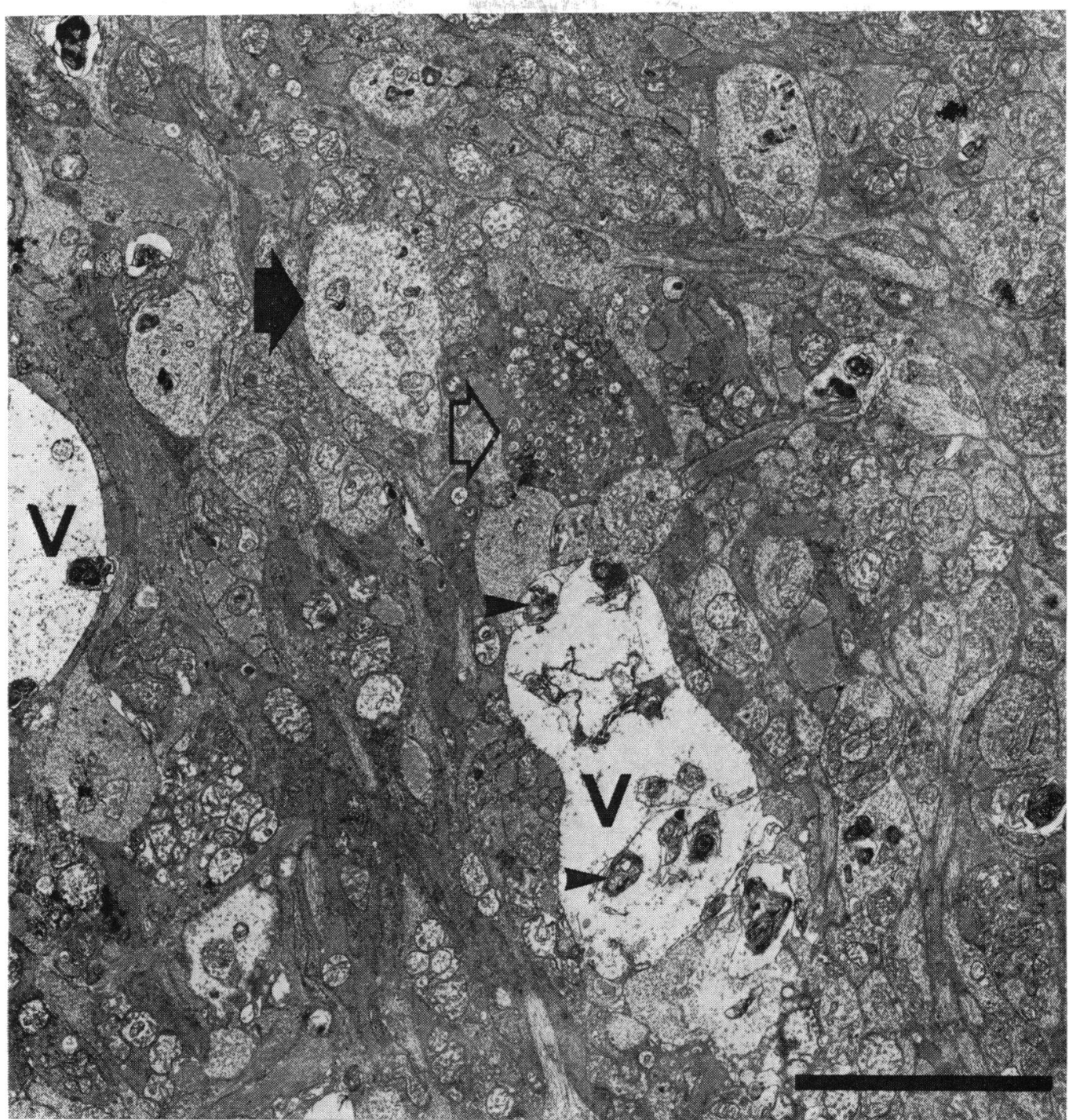

Fig. 5 Electron micrograph of laminar portion of nerve showing damage 5 hours after PCA occlusion. Vacuolation (V) and degenerate mitochondria (small arrows), together with both abnormally electron-dense (open arrow) and translucent (closed arrow) axonal swellings. (Bar marker is $4 \mu m$ )

Fig 4 Light micrographs of nerve showing damage 5 hours after temporal short PCA occlusion.

(a) Vacuolated nerve fibres in retrolaminar portion of nerve on temporal side only (designations as in Fig. 3; bar marker is $300 \mu \mathrm{m}$ ). (b) High-power view of vacuolated fibres from temporal retrolaminar nerve (solid arrow in Fig. 4a). (c) High power view of nasal fibres (open arrow in Fig. 4a; bar marker is $200 \mu \mathrm{m}$ )
CHRONIC HISTOPATHOLOGY

In 2 animals that survived for 4 and 7 days respectively after PCA occlusion and showed ischaemic damage (Table 1) both the microscopy and the autoradiography showed secondary changes which tended to obscure the focal distribution of the underlying pathogenic mechanisms.

In the prelaminar region swollen axonal stumps were observed some distance from the lamina, and on autoradiography these were identified as the sites at which orthograde axonal flow ceased (Fig. 
9a). Separating these swellings from the lamina was an area of vacuolation which had presumably arisen as a result of retrograde degeneration of injured axons. Thus the accumulation of radioactive material in the prelaminar regions was more diffuse in distribution, and more remote from the lamina, than in scute studies.

Secondary changes had begun to obscure the vacuolated areas in the laminar and immediate retrolaminar regions by the fourth postoperative

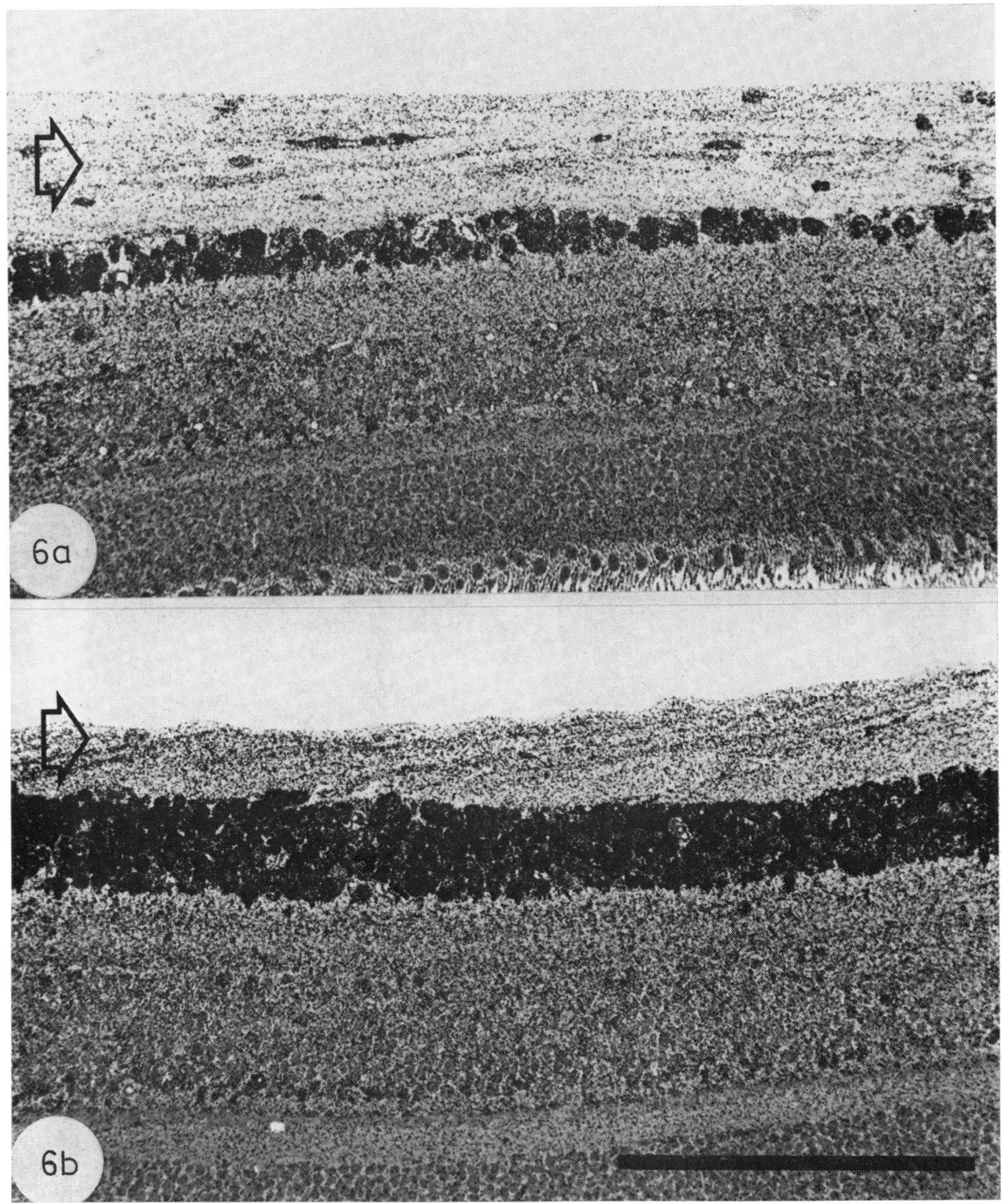

Fig. 6 Light microscopic autoradiographs of retina $5 \frac{1}{2}$ hours after intravitreal injection of tritiated leucine. Dense uptake of radioleucine into both ganglion-cell bodies and their axons (arrowed) from nasal (a) and temporal (b) areas of retina. (Bar marker is $200 \mu \mathrm{m}$ ) 


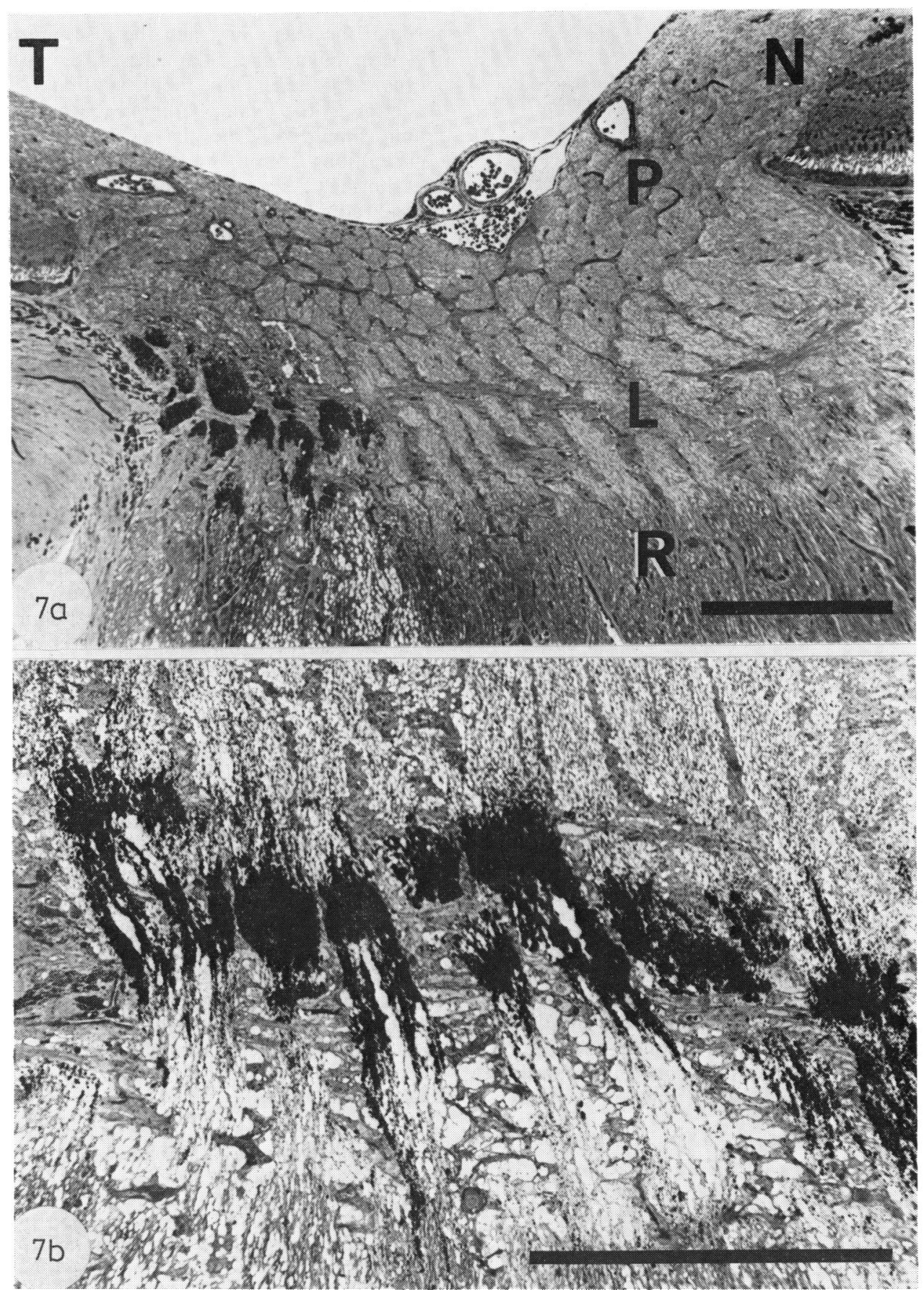

Fig. 7 Light microscopic autoradiographs of 2 nerves showing damage 5 hours after temporal short PCA occlusion and $5 \frac{1}{2}$ hours after intravitreal injection of tritiated leucine. (a) Accumulation of radioleucine in prelaminar and laminar portions of the nerve on temporal side (designations as in Fig. 3). (b) Higher power view of laminar portion of another nerve. (Bar markers are $200 \mu \mathrm{m})$ 


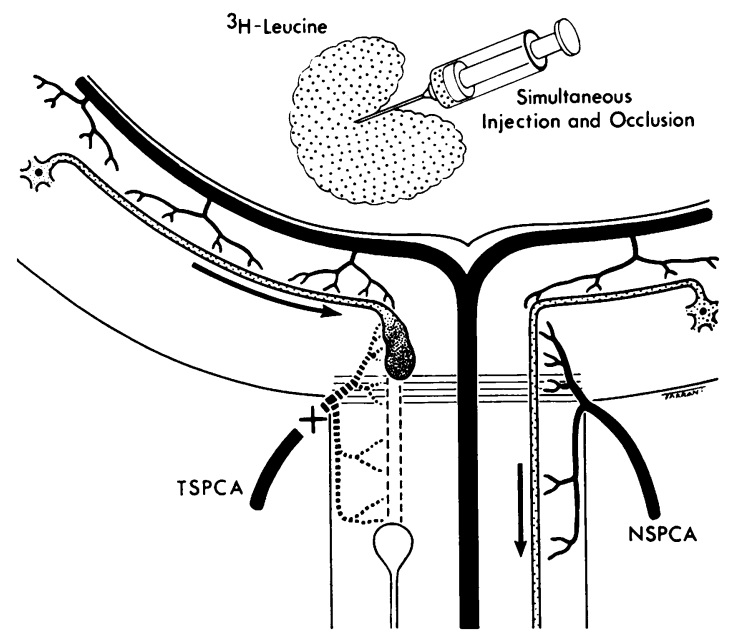

Fig. 8 Diagram of autoradiographic findings in retinal ganglion-cell axons after occlusion (X) of temporal short PCAs. Orthograde axoplasmic transport (arrows) obstructed in temporal prelaminar region adjacent to ischaemic vacuolation (axolemma dotted) in laminar and immediately retrolaminar regions. TSPCA $=$ temporal short posterior ciliary arteries. NSPCA = nasal short posterior ciliary arteries.

day. After 7 days some of the myelin sheaths had begun to degenerate, and macrophages were found in the retrolaminar nerve (Fig. 9b). In both eyes many axons immediately adjacent to the pia on the temporal side had relatively normal morphology and showed normal axonal flow characteristics in the autoradiographs (Fig. 9a). However, some sections showed obstruction in the form of dense areas of grain over swollen regions some way into the retrolaminar nerve.

Posterior to the ischaemic area the zone of swollen axonal stumps isolated from their cell bodies was extremely diffuse and therefore difficult to identify. The individual swollen axon stumps were tapered, unlike the spheroidal swellings observed in unmyelinated portions of axons in an earlier report. ${ }^{15}$

\section{Discussion}

\section{ARTERIAL SUPPLY TO THE ANTERIOR}

OPTIC NERVE

Apart from the superficial horizontal layer of nerve fibres both the optic disc and the immediately retrolaminar myelinated optic nerve obtain their blood supply from branches of the PCAs, which usually arise as 2 or 3 main trunks from the ophthalmic artery. ${ }^{3}$ Those short ciliary branches destined to supply the optic nerve head pass either directly through the sclera or reach the disc indirectly via the peripapillary choroidal arteries; the latter route is more prominent in monkeys than in man. ${ }^{16}$ Posterior to the lamina cribrosa the optic nerve is mainly supplied by the pial plexus, which receives contributions from many orbital arteries, including the short PCAs and extraneural branches of the central retinal artery (CRA). In addition a relatively insignificant axial supply from branches of the intraneural CRA has been described in man.17 However, no intraneural branches of the CRA were found in various monkey species, ${ }^{1819}$ and recent studies of blood flow using a heated thermocouple technique indicate that the short PCAs indeed provide the major vascular supply to the immediately retrolaminar part of the optic nerve in the rhesus monkey. ${ }^{20}$

Each PCA normally supplies a defined territory with relatively little overlap in the area supplied. ${ }^{17}$ This 'segmental distribution' has been clearly demonstrated in the peripapillary choroid after intracarotid fluorescein injection in monkeys ${ }^{21}$ and in the initial frames of intravenous fluorescein angiograms after occlusion of several short PCAs, as in this study. Such experiments also indicate that the transversely orientated ciliary circulation to the lamina cribrosa may be sectoral. However, the prelaminar and retrolaminar vascularity also has a prominent anteroposterior orientation and continuity in addition to the transverse sectoral pattern emphasised by Hayreh. ${ }^{16}$

It has been claimed that each PCA acts functionally as an 'end-artery'22 - that is, as an independent arteriolar-capillary unit with no available interarterial or other precapillary anastomoses. After PCA occlusion necrosis would therefore be expected throughout the vascular territory, any capillary connections being insufficient to maintain tissue viability. There is, however, abundant anatomical evidence of arteriolar anastomoses both between individual branches of the PCAs, for example, an

Fig. 9 Light micrographs of nerve showing damage several days after temporal short PCA occlusion. (a) Autoradiograph of nerve 4 days after PCA occlusion and intravitreal injection of tritiated leucine; section through inferotemporal quadrant of optic nerve head. Accumulation of radioactive material retracted away from lamina cribrosa into prelaminar region; flow of label into retrolaminar portion of nerve in axons adjacent to pia (arrowed). (Designations as in Fig. 3; bar marker is $300 \mathrm{um}$ ). (b) Light micrograph of retrolaminar portion of nerve 7 days after PCA occlusion; macrophages (arrowed) in damaged temporal portion of nerve. (Bar marker is $500 \mu \mathrm{m}$ ) 

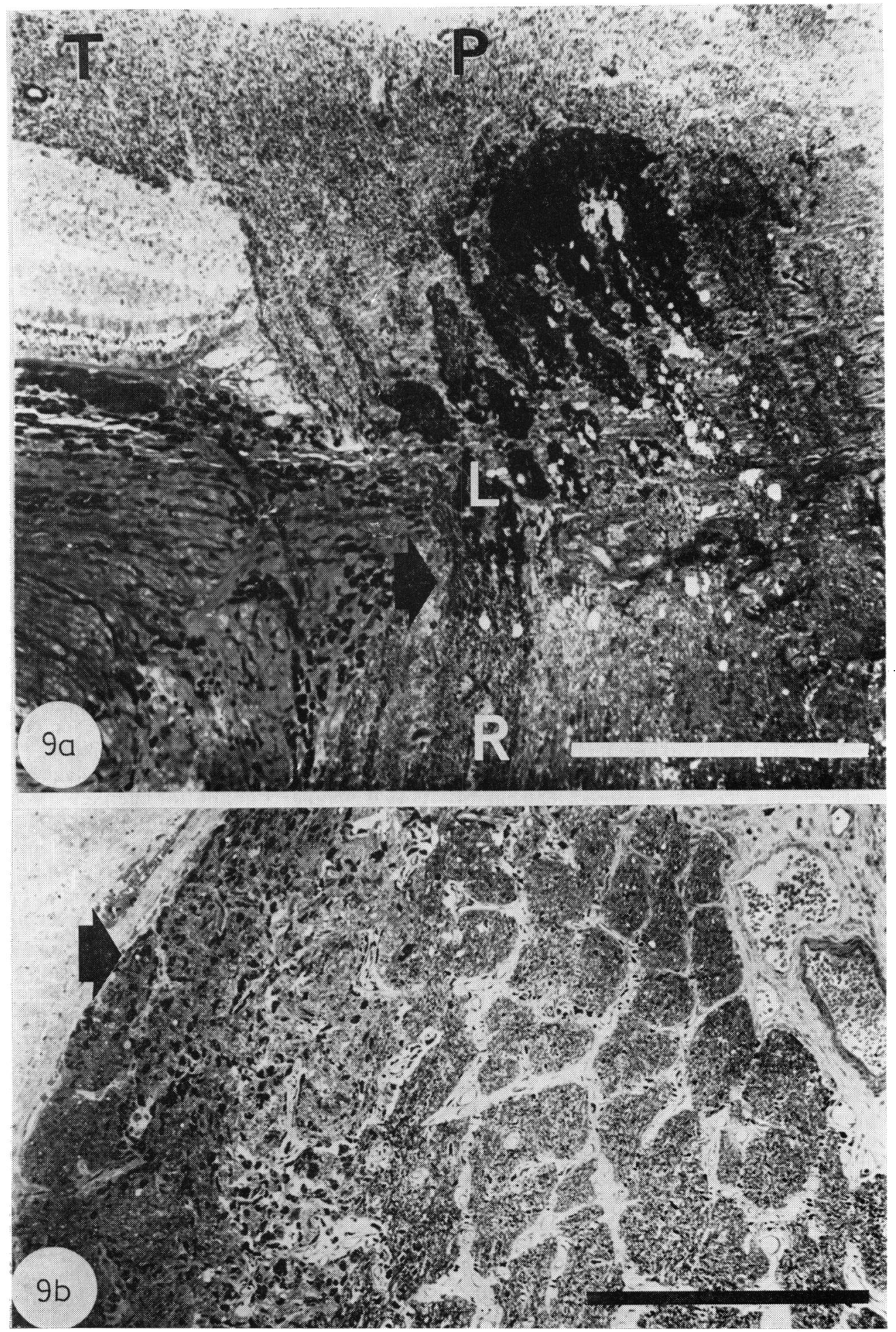
incomplete intrascleral arterial circle of Zinn and an arterio-arteriolar network in the peripapillary choroid, ${ }^{23}$ and also between the PCAs and adjacent arterial circulations, for example, via the posterior episcleral plexus and the pial plexus. ${ }^{22}$ That these anastomoses are indeed 'functional' after PCA occlusion is demonstrated by the fact that ischaemic damage is restricted to triangular patches of outer retina and in only a proportion of animals to sectors of the optic nerve. The various individual routes of collateral arterial supply after PCA occlusion have been demonstrated by latex and silicone rubber injection studies. ${ }^{22} 24$ These pathways may underlie the delayed filling of the temporal peripapillary choroid consistently found in our study in the late venous phase of fluorescein angiograms performed less than an hour after temporal short PCA occlusion. This pattern has also been described by Ernest and others, ${ }^{25}$ though delayed filling of the temporal choriocapillaris was noted in only a minority of the animals studied by Hayreh and Baines. ${ }^{22}$

In those eyes with optic nerve damage after PCA occlusion ischaemic vascuolation was found only in the laminar and retrolaminar regions early after occlusion. This anteroposterior localisation of infarction had not been apparent from previous histological studies in which optic nerve changes were assessed several weeks after PCA occlusion. Hayreh and Baines ${ }^{26}$ merely assumed that the ischaemic zone had included the prelaminar region in addition to the retrolaminar myelinated optic nerve, while Anderson and Davis ${ }^{27}$ supposed that infarction of the optic disc was the cause of the ascending neuronal degeneration seen in the orbital part of the optic nerve. An explanation for the absence of ischaemic damage anterior to the lamina cribrosa 5 hours after PCA occlusion is not readily forthcoming, since prelaminar infarction might have been anticipated from the known distribution of the PCA supply. ${ }^{17}$ The preservation of neuronal viability anterior to the lamina cribrosa must reflect the effectiveness of collateral arterial connections (rather than provision of nutrients from other sources such as the vitreous). Anastomosis with the CRA circulation is the likeliest source of collateral supply, though this was virtually impossible to assess by fluorescein angiography in our experiments and was not apparent to Hayreh and Baines $^{26}$ in their silicone rubber injection studies. However, the demonstration of cilioretinal anastomosis after CRA occlusion ${ }^{28}$ is in keeping with this suggestion.

The anteroposterior extent of retrolaminar infarction was variable, but was of a similar dimension to the zone of nonfilling by silicone rubber noted by
Hayreh and Baines. ${ }^{26}$ The extent of necrosis also correlated with the reduction in tissue $\mathrm{Po}_{2}$ noted in the optic nerve 3-4 mm behind the eye by Armaly and $\mathrm{Araki}^{20}$ after short PCA occlusion.

\section{NATURE OF ISCHAEMIC DISC SWELLING}

Those eyes showing ischaemic damage after PCA occlusion had prelaminar changes of a fundamentally different nature from the infarct of the retrolaminar myelinated optic nerve. The unmyelinated ganglion-cell axons became swollen with neurofilaments and organelles but were not disrupted. Autoradiographic studies demonstrated an associated obstruction of orthograde axoplasmic transport and also confirmed that the boundary between viable and ischaemic axon segments after PCA occlusion was situated at the lamina cribrosa (and not more superficially). In acute lesions (i.e., after 5 hours) rapidly transported ${ }^{3} \mathrm{H}$-leucine accumulated at the lamina cribrosa proximal to the retrolaminar infarct, while in survival experiments obstruction of slow axonal transport also contributed to the generalised accumulation of ${ }^{3} \mathrm{H}$-leucine in the optic nerve head.

Levy ${ }^{29}$ also described an obstruction of slow ${ }^{3} \mathrm{H}$-leucine transport at the lamina cribrosa after PCA occlusion in rhesus monkeys. The relationship of this obstruction to changes in the retrolaminar myelinated optic nerve was not defined, however, and several other observations, for example, presence of macular oedema and subretinal haemorrhages, but absence of outer retinal damage, make Levy's findings difficult to interpret. A laminar obstruction of slow and rapid orthograde axoplasmic transport has also been described in papilloedema from raised intracranial pressure ${ }^{30}$ and in ocular hypertension and hypotony. ${ }^{3132}$ In these conditions, however, the continuity of ganglion-cell axons was not disrupted (at least in the initial stages), the axoplasmic transport block was incomplete, and mechanical rather than ischaemic obstruction of axoplasmic transport has been postulated.

Our histological and autoradiographic findings in the prelaminar region after PCA occlusion are similar to those in the retinal nerve-fibre layer adjacent to areas of experimental inner retinal ischaemia. ${ }^{15}$ Furthermore, the clinical appearance of the acutely swollen ischaemic disc is identical to that of the retinal cotton-wool spot. Ischaemic disc swelling and retinal cotton-wool spots both represent accumulations of axoplasmic debris adjacent to infarcts involving retinal ganglion-cell axons. This correlates with necropsy findings in patients dying within a few days of onset of visual loss from ION (Fig. 10). Kreibig ${ }^{4}$ was the first to describe the pale retrolaminar infarct of the myelinated optic nerve: 


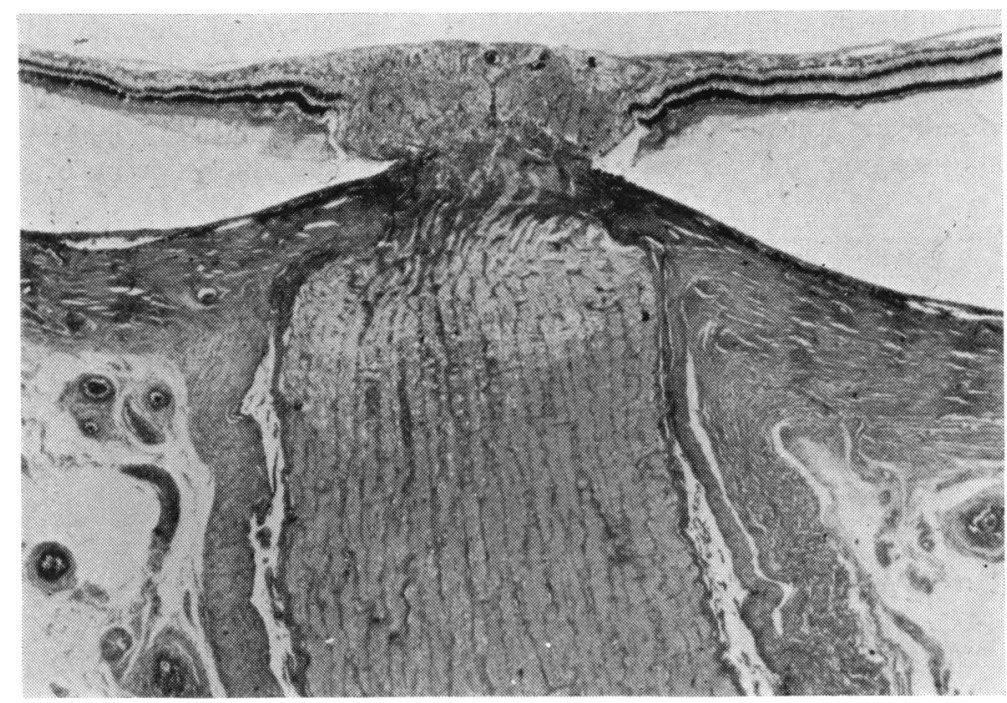

Fig. 10 Histopathology of human optic nerve 6 days after total visual loss from temporal arteritis. Retrolaminar infarction; prelaminar axonal swelling; arteritic occlusion of PCAs (courtesy of Professor Alec Garner). in such cases while Rodenhauser" noted 'cytoid bodies' (i.e., accumulations of axoplasm) in the prelaminar region.

The development of disc swelling after PCA occlusion depends on continuing orthograde axoplasmic transport in the nerve-fibre layer of the retina, so sufficient blood must continue to flow through branches of the CRA in order to maintain this transport function in the ganglion-cell axons. This is confirmed by clinical observation in cases of simultaneous combined CRA and PCA occlusion (where no opaque disc swelling develops). Similarly, in patients in whom ION is associated with occlusion of a large cilioretinal artery, no white swelling develops in the sector of the disc contiguous with the inner retinal infarct, ${ }^{13}$ so the translucent infarct of the inner retina and disc is continuous with that in the retrolaminar optic nerve.

It appears that the principal sign of ION, namely, pale disc swelling, can be entirely attributed to an accumulation of axoplasm in the prelaminar region. However, part of the disc swelling was recently attributed to infarction of the peripapillary pigment epithelium. ${ }^{11}{ }^{17}$ This view was based on stereophotography of acutely ischaemic discs and the observation of pigmentary peripapillary degeneration at the stage of optic atrophy. It is significant, however, that identical pigmentary changes were present around the optic discs of the unaffected eyes in each of the cases presented by Hayreh in support of his contention. The absence of peripapillary pigment epithelial changes adjacent to ischaemic nerves after PCA occlusion in this study further denies the general concept proposed by Hayreh, though the authors are aware of rare authentic clinical examples of peripapillary outer retinal infarction associated with ION.

SEGMENTAL ISCHAEMIC OPTIC NEUROPATHY This concept is based on the transverse vascular architecture of the optic disc and signifies involvement of only a sector (rather than the whole) of the optic nerve head. Thus occlusion of part of the posterior ciliary supply (as in this study) may result in infarction within the territory of supply of the obstructed vessels, collateral circulation being insufficient to maintain tissue viability within the ischaemic area. There is no doubt that such cases occur in clinical practice (Fig. 11), although, unlike experimental PCA occlusion, ischaemic damage is usually confined to the optic nerve head (with no infarction of the outer retina). It has been suggested, however, that the typical visual field defect resulting from such an occlusion is a hemianopia whose vertical border passes through the blind spot, peripapillary choroidal ischaemia contributing to the field loss. ${ }^{1721}$ We have been unable to confirm such a field defect clinically, however, and our autoradiographic studies of photoreceptor function after PCA occlusion fail to lend support to the concept that an absolute visual field defect would result from a degree of choroidal ischaemia insufficient to cause outer retinal infarction (Marshall, McLeod, and Kohner, in preparation).

Many patients with sectoral ischaemic optic neuropathy present with an inferior altitudinal hemianopia associated with pale swelling (and subsequent atrophy) of the superior half of the optic disc. Hayreh ${ }^{17} 21$ has repeatedly suggested that such an altitudinal hemianopia results from occlusion of 
a main PCA supplying the upper half of the choroid and optic disc. However, this view has been justified only by the choroidal filling pattern seen after intracarotid fluorescein injection in two monkeys which had previously undergone orbital dissection and
CRA occlusion..$^{21}$ No such pattern of choroidal and disc filling has been seen in patients with altitudinal hemianopia, nor have anatomical studies revealed any horizontal division of the main PCA supply.21

Hayreh $^{17}$ chose to illustrate the concept of a
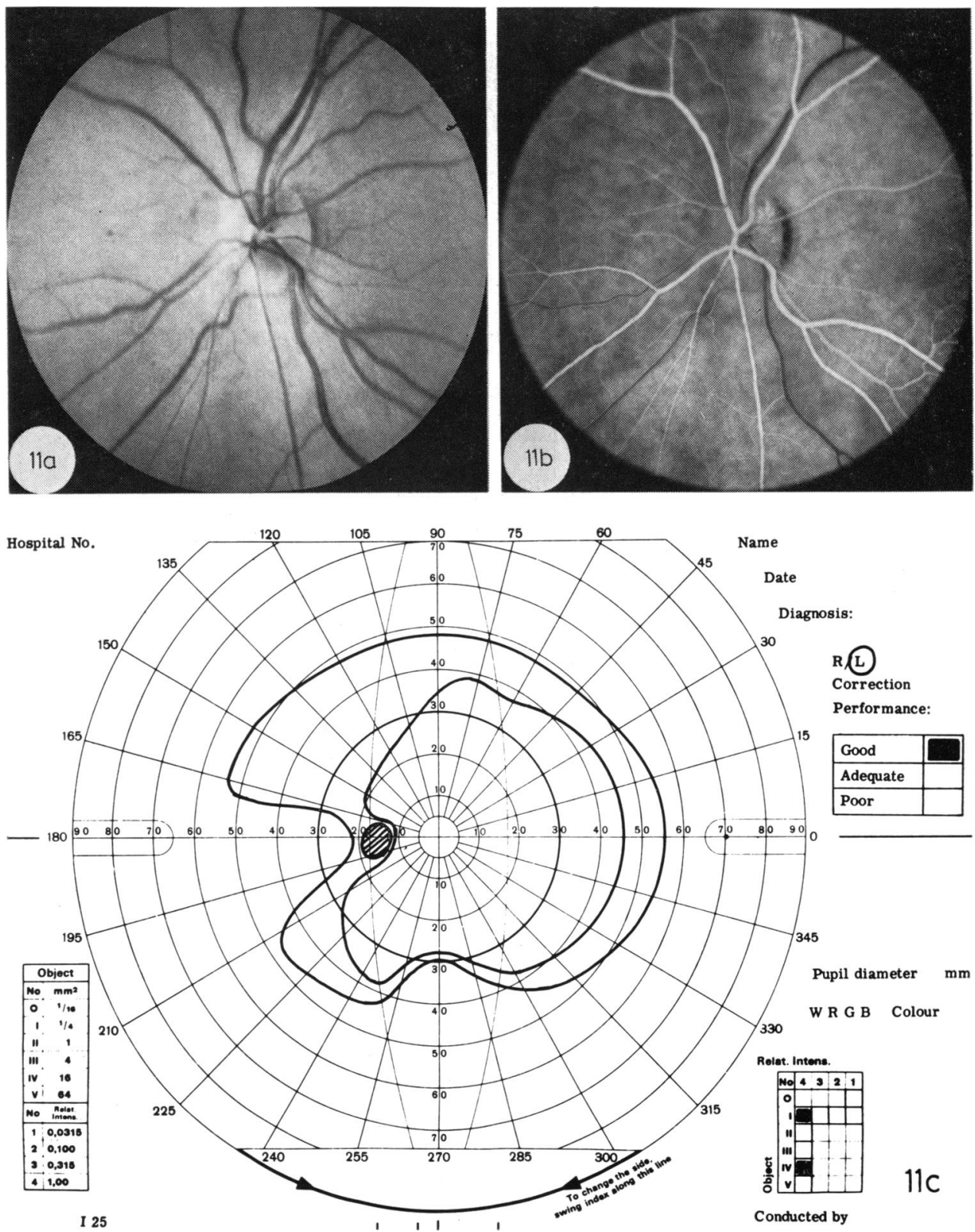

Fig. 11 Case of segmental ischaemic optic neuropathy. (a) Photograph of left optic disc; opaque swelling of prelaminar tissue nasally. (b) Fluorescein angiogram (arteriovenous phase); delayed filling of choriocapillaris in territory of medial PCA. (c) Goldmann perimetry; nerve-fibre bundle defects (courtesy of Professor Alan Bird) 
segmental ION with a patient in whom vision was totally lost from PCA occlusion but in whom no accumulation of axoplasm occurred in that half of the disc that was contiguous with a large cilioretinal infarct. The disc appearance, however, depended on the underlying nature of ischaemic disc swelling, ${ }^{13}$ and the use of the term 'segmental ION' in such a case seems unwarranted. Hayreh ${ }^{\mathbf{1 1} 17}$ has also described examples of so-called 'sectoral ION' contiguous with infarcts of inner retina supplied by cilioretinal arterioles. It is likely, however, that these were cases of pure cilioretinal artery occlusion and that the disc swelling represented an accumulation of axoplasm resulting from obstruction of retrograde axoplasmic transport. Such an opaque accumulation of axoplasm in the optic nerve head after cilioretinal artery occlusion (and also after hemisphere branch retinal artery occlusion and CRA occlusion) should not be designated 'ION' even though the disc swelling is of a fundamentally similar nature.

We are grateful to Messrs P. L. Ansell and P. West and Ms E. Clarke and M. Foster for technical assistance; to Messrs T. Tarrant, K. Sehmi, and T. Bandle for photographic assistance; and Miss P. Davies for secretarial assistance.

This work was supported by a grant from the Medical Research Council. We gratefully acknowledge gifts of technical apparatus from the British National Committee for Prevention of Blindness, the Garrick Trust, and the Wellcome Trust.

\section{References}

${ }^{1}$ Meadows SP. Temporal arteritis and loss of vision. Trans Ophthalmol Soc UK 1954; 74: 13-24.

${ }^{2}$ Foulds WS. Visual disturbances in systemic disordersoptic neuropathy and systemic disease. Trans Ophthalmol Soc UK 1969; 89: 125-46.

${ }^{3}$ Hayreh SS. Blood supply of the optic nerve head and its role in optic atrophy, glaucoma and oedema of the optic disc. Br J Ophthalmol 1969; 53: 721-45.

${ }^{4} \mathrm{Kreibig}$ W. Optikomalazie; die folge eines gefabverschlusses im retrobulbären abschnitt des sehnerven. Klin Monatsbl Augenheilk 1953; 122: 719-31.

${ }^{5}$ Crompton MA. The visual changes in temporal (giant cell) arteritis. Brain 1959; 82: 377-90.

espencer WH, Hoyt WF. A fatal case of giant cell arteritis (temporal or cranial arteritis) with ocular involvement. Arch Ophthalmol 1960; 64: 862-7.

${ }^{\prime}$ Rodenhäuser JH. Uber pathologisch-anatomische augenveranderungen bei generalisierter riesenzellarteriitis. Klin Monatsbl Augenheilk 1964; 145: 414-29.

${ }^{8}$ Cogan DG. Neurology of the Visual System. Springfield: Thomas, 1966.

'Knox DL, Duke JR. Slowly progressive ischaemic optic neuropathy: a clinico-pathological case report. Trans Am Acad Ophthalmol Otolaryngol 1971; 75 : 1065-8.

${ }^{10}$ MacMichael IM, Cullen JF. Pathology of ischaemic optic neuropathy. In: Cant JS, ed. Proceedings of the 2nd William MacKenzie Symposium on the Optic Nerve. London: Kimpton, 1972; 108-16.

${ }^{11}$ Hayreh SS. Anterior ischaemic optic neuropathy. II. Fundus on ophthalmoscopy and fluorescein angiography. Br J Ophthalmol 1974; 58: 964-80.

${ }^{12}$ McLeod D. Clinical sign of obstructed axoplasmic transport. Lancet 1975 ; 2 : 954-6.

${ }^{13}$ McLeod D. Ophthalmoscopic signs of obstructed axoplasmic transport after ocular vascular occlusions. $\mathrm{Br} J$ Ophthalmol 1976; 60: 551-6.

${ }^{14}$ Kohner EM, Dollery CT, Shakib M, et al. Experimental retinal branch vein occlusion. Am J Ophthalmol 1970; 69: 778-825.

${ }^{15}$ McLeod D, Marshall J, Kohner EM, Bird AC. The role of axoplasmic transport in the pathogenesis of retinal cotton-wool spots. Br J Ophthalmol 1977; 61: 177-91.

${ }^{16}$ Lieberman MF, Maumanee AE, Green WR. Histological studies of the vasculature of the anterior optic nerve. Am J Ophthalmol 1976; 82: 405-23.

${ }^{17}$ Hayreh SS. Anterior Ischaemic Optic Neuropathy. New York: Springer, 1975.

${ }^{18}$ Hayreh SS. The orbital vessels of Rhesus monkeys. Exp Eye Res 1964 ; 3: 16-30.

${ }^{19}$ Anderson DR. Vascular supply to the optic nerve of primates. Am J Ophthalmol 1970; 70: 341-51.

${ }^{20}$ Armaly MF, Araki M. Optic nerve circulation and ocular pressure: contribution of central retinal artery and short posterior ciliary arteries and effect on oxygen tension. Invest Ophthalmol 1975; 14: 475-9.

${ }^{21}$ Hayreh SS. Pathogenesis of visual field defects--role of the ciliary circulation. Br J Ophthalmol 1970; 54: 289-311.

${ }^{22}$ Hayreh SS, Baines JAB. Occlusion of the posterior ciliary artery. I. Effects on choroidal circulation. Br J Ophthalmol 1972; 58: 719-35.

${ }^{23}$ Shimizu K, Ujiie K. Structures of Ocular Vessels. Tokyo, New York: Igaku-Shoiu, 1978.

${ }^{24}$ Wybar KC. Vascular anatomy of the choroid in relation to selective localisation of ocular disease. $\mathrm{Br} J$ Ophthalmo 1954; 38: 513-27.

${ }^{25}$ Ernest JT, Stern WH, Archer DB. Submacular choroidal circulation. Am J Ophthalmol 1976; 81: 574-82.

${ }^{26}$ Hayreh SS, Baines JAB. Occlusion of the posterior ciliary artery. III. Effects on the optic nerve head. Br J Ophthalmol 1972; 58: 754-64.

${ }^{27}$ Anderson DR, Davis EB. Retina and optic nerve after posterior ciliary artery occlusion. Arch Ophthalmol 1974; 92: 422-6.

${ }^{28}$ Van Heuven WAJ, Hayreh MS, Hayreh SS. Experimental central retinal vascular occlusion. Trans Ophthalmol Soc UK 1978; 97: 588-618.

${ }^{29}$ Levy NS. The effect of interruption of the short posterior ciliary arteries on slow axoplasmic transport and histology within the optic nerve of the rhesus monkey. Invest Ophthalmol 1975; 15: 495-9.

${ }^{30}$ Tso MOM, Hayreh SS. Optic disc oedema in raised intracranial pressure. IV. Axoplasmic transport in experimental papilloedema. Arch Ophthalmol 1977; 95: 1458-62.

${ }^{31}$ Anderson DR, Hendrickson A. Effect of intraocular pressure on rapid axoplasmic transport in monkey optic nerve. Invest Ophthalmol 1974; 13: 771-83.

${ }^{32}$ Minkler DS, Bunt AH, Klock IB. Radioautographic and cytochemical ultrastructural studies of axoplasmic transport in the monkey optic nerve head. Invest Ophthalmol 1978; 17: 33-50. 